\title{
EL DELITO DE SEDICIÓN COMO HERRAMIENTA DE PERSECUCIÓN JUDICIAL EN LOS AÑOS FINALES DE LA DOMINACIÓN ESPAÑOLA EN HONDURAS
}

\section{THE CRIME OF SEDITION AS A TOOL FOR JUDICIAL PERSECUTION IN THE FINAL YEARS OF SPANISH RULE IN HONDURAS}

\author{
José Manuel Cardona Amaya ${ }^{1}$ \\ DOI: https://doi.org/10.5377//rd.v42i1.12925
}

\section{RESUMEN}

El Bicentenario de la Independencia de Centroamérica, celebrado en este año de 2021, invita a reflexionar sobre el contexto histórico en que fue declarada la libertad de esas provincias. En esta investigación se propone estudiar cómo los funcionarios de la monarquía utilizaban el delito de sedición para perseguir judicialmente a las personas que se oponían al régimen del Imperio Español. Para este propósito se rastrea la evolución del delito de sedición en el derecho castellano y cómo este fue adaptado para su aplicación en América, pasando posteriormente a estudiar los casos. Esta exploración permite demostrar que los años finales de la dominación española en Honduras fueron tumultuosos y que los operadores de justicia jugaron un importante papel en la supresión de los movimientos rebeldes. Metodológicamente se adopta una perspectiva histórica, ofreciéndose un análisis basado en fuentes documentales de la época.

PALABRAS CLAVE: bicentenario, sedición, Honduras, política, persecución

\section{ABSTRACT:}

The Bicentennial of the Independence of Central America, celebrated in this year of 2021, invites reflection on the historical context in which the freedom of those provinces was declared. In this research it is proposed to study how the officials of the monarchy used the crime of sedition to judicially prosecute people who opposed the regime of the Spanish Empire. For this purpose, the evolution of the crime of sedition is traced in Castilian law and how it was adapted for its application in America, going on to study the cases later. This exploration shows that the final years of Spanish domination in Honduras were tumultuous and that justice officials played an important role in suppressing the rebel movements. Methodologically a historical perspective is adopted, offering an analysis based on documentary sources of the time.

KEYWORDS: bicentennial, sedition, Honduras, politics, persecution

Fecha de recepción: $6 / 2 / 2021$ Fecha de aprobación: 28/10/2021

\footnotetext{
${ }^{1}$ Docente del Departamento de Historia, Licenciado en Historia, Universidad Nacional Autónoma de Honduras, Correo: jmcardona@unah.edu.hn
} 


\section{INTRODUCCIÓN}

En el año 2021 se celebra el bicentenario de la Independencia de Centroamérica, habiéndose separado esta región del Imperio Español en 1821. La percepción popular de este evento es que fue una transición pacífica e inesperada, declarada por las elites criollas sin consultar a la población en general. De esta visión tradicional se excluye que, desde la primera década del siglo XIX, Centroamérica había vivido ya varios brotes revolucionarios a nivel local y que las autoridades españolas se encontraban asediadas por las constantes amenazas de alzamientos. En este contexto de inestabilidad, los españoles emplearon el delito de sedición como herramienta de persecución judicial, acusando a todos aquellos que se opusieron al régimen dominante y silenciando a cualquier elemento disidente que surgiera.

En este artículo se exponen tres casos próximos a la Independencia de Centroamérica en los cuales los acusados fueron señalados del delito de sedición por las autoridades españolas locales, con el propósito de ilustrar como la situación política de los años finales del dominio español condujo a un aumento de la persecución de los rebeldes. Esta visión contrasta con el panorama bucólico propuesto por la historiografía tradicional, en la cual los años previos a la Independencia se vivieron en suma paz y con ninguna sospecha de los dominadores de los deseos de libertad de la población. Al contrario, se propone con esta investigación demostrar que los funcionarios españoles en Honduras se encontraban en un estado de alerta constante, dando persecución a cualquier rumor de aparecimiento de ideas independentistas en la población.
El enfoque principal de esta investigación es la aplicación de las leyes contra la sedición por los funcionarios españoles en Honduras, presentándose los resultados en la forma de un análisis histórico. Se han utilizado tres casos de la época: uno de 1811, correspondiente al periodo de la Guerra de Independencia Española; un segundo caso de 1817, perteneciente al interregno absolutista de Fernando VII y; un tercer caso de 1820 , enmarcado en el periodo conocido como el "trienio liberal", en el cual la Constitución de la Monarquía española estuvo vigente. De esta manera, se ha abordado el delito de sedición en tres contextos distintos, reflejando esto la frágil situación política del Imperio Español y su débil control sobre la Honduras de este periodo.

\section{PLANTEAMIENTO DEL PROBLEMA}

El delito de sedición tiene una larga historia en el derecho español, siendo relacionado con la rebelión contra el Rey desde los primeros textos jurídicos hispánicos y diferenciado de este hasta tiempos modernos. En el Fuero Juzgo de 1241, traducción al romance del Liber Iudiciorum, se hace especial censura de aquellos siervos que intentasen apropiarse de la casa de su patrón y de aquellos que reuniesen otras personas para oponerse a su señor (Fuero Juzgo, 1815). Esta primera formulación del delito respondía al contexto histórico del reino de Visigodo en el siglo VIII, siendo esta entidad política un territorio de poco tamaño, eminentemente rural y con una forma de feudalismo incipiente.

Posteriormente, los juristas castellanos plantearon la definición de "asonada" que se consignó en Las Siete Partidas del Rey Alfonso el Sabio, diferenciando este documento entre levantamientos benéficos -aquellos hechos contra 
los enemigos del Rey- y alzamientos criminales -aquellos efectuados entre los mismos vasallos del monarca- (Las Siete Partidas del Rey Alfonso, 1843, p.304). En cuanto a la rebelión contra el Rey o la sedición de su reino, en la Ley I del Título II de la Séptima Partida se iguala la traición al Rey con el crimen de lesa majestad:

Laesae maiestatis crimen en latín tanto quiere decir en romance como yerro de traycion [sic] que face [sic] home [sic] contra la persona del rey. Et traycion [sic] es la mas vil cosa que puede caer en el corazón de home [sic]: et nascen [sic] della [sic] tres cosas que son contrarias de la lealtad, et son estas: tuerto, et mentira et vileza. (Las Siete Partidas del Rey Alfonso, 1843b, p.443-444).

Este delito de alzarse contra el Rey era castigado con la pena capital y, después de ejecutado el sedicioso, se debían decomisar sus bienes y pasar el dote de su mujer al tesoro real y, no bastando con esto, los hijos del rebelde serían por siempre excluidos de cualquier privilegio $\mathrm{y}$ dignidad dentro del reino (Las Siete Partidas del Rey Alfonso, 1843b, p.446-448). Si bien alzarse contra el Rey era un crimen grave, también hablar mal del monarca era considerado un delito, como se consigna en la Ley VI del Título II de la Séptima Partida. Para estos criminales que hablaban mal del Rey, las Partidas recomendaban un castigo ejemplar y público, que sirviera de ejemplo para todos aquellos que pretendían también difamar al monarca.

Las leyes anteriores configuraron como evolucionó la concepción del delito de sedición en la ley castellana, no obstante, una vez los españoles comenzaron a emitir legislación única para América, se presentaron ciertas particularidades ausentes de los códigos europeos. En la Ley XLIV del Título XVI del Libro II de la Recopilación de Leyes de Indias, se dio potestad a los virreyes para obrar contra los sediciosos, presentándolos ante la Audiencia correspondiente, sin embargo, se le prohibió de aplicar el castigo de destierro sin antes haber consultado con el Consejo de Indias (Recopilación de Leyes de Indias, 1841, p.246). En la Ley XXVI del Título V del Libro VII, el Rey ordenó que en cuando la sedición fuera encabezada por un afrodescendiente, no se debía de seguir el proceso judicial ordinario, sino que el juez estaba obligado a mandar a ejecutar al líder de la rebelión sin un proceso, para que este sirviera de ejemplo a los demás (Recopilación de Leyes de Indias, 1841b, p.325).

En cuanto a los indígenas que se alzasen contra la Corona, la Recopilación de Leyes de Indias proveía penas leves, inclusive, recomendado que estos se perdonasen, como se lee a continuación:

Mandamos a los virreyes, audiencias, y gobernadores, que si algunos indios anduvieren alzados, los procuren reducir, y atraer a nuestro real servicio con suavidad $\mathrm{y}$ paz, sin guerra, robos, ni muertes; y guarden las leyes por Nos dadas para el buen gobierno de las Indias, y tratamiento de los naturales; y si fuere necesario otorgarles algunas libertades, o franquezas de toda especie de tributo, lo puedan hacer y hagan, por el tiempo y forma, que les pareciere, $\mathrm{y}$ perdonar los delitos de rebelión, que hubieren cometido. (Recopilación de Leyes de Indias, 1841b, p.30).

Una vez la casa de Borbón accedió al trono, las leyes contra la sedición se endurecieron. El 17 de abril de 1774, Carlos III expidió un largo decreto en el cual eliminaba todos los tribunales privilegiados en los casos de sedición y ordenaba 
que los culpables fueran procesados por la justicia ordinaria (Novísima Recopilación de Leyes de España, 1805, p.339). En ese mismo decreto, el Rey declaró que todos aquellos que escucharan expresiones sediciosas debían de denunciarlas inmediatamente y, de no hacerlo, serían considerados ellos mismos cómplices de la rebelión. El 18 de diciembre de 1804, Carlos IV prohibió la elaboración y distribución de pasquines sediciosos en contra de la monarquía, coartando de esta manera la libertad de expresión de sus súbditos (Novísima Recopilación de Leyes de España, 1805, pp.417-418). Estas nuevas leyes para combatir la sedición estaban ancladas en el ambiente inestable de los últimos años del Imperio español, enfrentando insurrecciones en la misma España, en Suramérica y en México.

Finalmente, la Constitución Política de la Monarquía Española aprobada en 1812 y, una vez más, en 1820, establecía en su Título IV, Capítulo I, Artículo 168 la inviolabilidad y sacralidad del Rey, entendiéndose por esto no solamente la persona física del monarca, sino que su figura en el espacio público (Constitución Política de la Monarquía Española, 1812). Esta ley limitaba la participación discursiva de los súbditos del monarca, forzándolos a ceñirse a criticar a los funcionarios locales y excluyendo al Rey de cualquier culpa de la mala administración. En cuanto a su aplicación para la sedición, esta ley se añadió al resto de decretos ya expedidos por la casa de Borbón, sumando al ambiente represivo de los años finales del dominio del Imperio Español en Honduras.

\section{METODOLOGÍA}

Según Lobban (2012), el estudio de la historia del derecho se puede dividir en dos corrientes: aquellas que estudian la evolución de la doctrina jurídica y aquellas que se enfocan en la aplicación de la ley y el impacto que esta tiene en la vida de las personas. En el presente artículo se adoptará esta segunda corriente de estudio, enfocándose el análisis en cómo los funcionarios locales aplicaron las leyes contra la sedición para reprimir las críticas que la población hacía a la Corona española. En cuanto a la presentación de la información se seguirá la definición que White (1981) hace de la narrativa histórica, planteándola como la nueva interpretación de una serie particular de hechos para lograr un discurso cohesivo.

La selección de la información ha sido hecha en apego a la propuesta de Baker (2012), quien expone que el estudio de casos representa una de las vías más directas para comprender cómo se entendía y aplicaba la legislación en determinada época. Por lo tanto, se han tomado tres casos, uno de 1811 , otro de 1817 y un último de 1820 para explorar la manera en que los funcionarios políticos perseguían la sedición mediante procesos judiciales.

\section{RESULTADOS DE INVESTIGACIÓN}

El primer caso aquí estudiado sucedió en 1811 en Nacaome, cuando un señor llamado Joaquín de San Martín denunció a su vecino llamado José Gabriel Vela, por haber proferido palabras sediciosas en contra de España. La fecha del suceso es relevante, porque en esos años España se batía en contra de Francia en su propia guerra de Independencia, exacerbando el espíritu nacionalista de sus provincias, pero también dando paso a la aparición de las disidencias. Estos sentimientos patrióticos se extendieron hasta Honduras, siendo testimonio de esto la misma declaración del denunciante, quien afirmó que acusó a su vecino obedeciendo a "mi lealtad y 
patriótico amor a nuestra sagrada religión, a nuestro soberano Augusto Fernando Séptimo y a nuestra nación española" (Lindo, 1811, p.2). Denunciar las expresiones sediciosas era algo motivado por los poderes políticos, quienes habían jurado lealtad a las Cortés de Cádiz y al Rey exiliado, renegando del gobierno bonapartista en España. No obstante, Napoleón había ganado adeptos en las tierras americanas, por considerársele un modernizador de los sistemas políticos europeos que se habían estancado en el absolutismo monárquico. En específico, se acusó a José Vela de decir que:

El héroe talentoso e ingenioso Bonaparte será memorable y laudable sobre todas las historias de las testas coronadas y que conquistará con sus formidables ejércitos la España y sus dominios y será Rey y señor de ella: que las noticias por gacetas de España que refieren hechos favorables a ella son imposturas falsas para que los de América manden dinero para invertirlo en sus comercios o particulares utilidades desprendidas de la guerra. (Lindo, 1811, p.3).

La ley que José Vela quebrantaba era el decreto de 17 de abril de 1774 expedido por Carlo III, que prohibía a las personas de pronunciarse públicamente contra la Corona y ordenaba a todos aquellos que escucharan expresiones sediciosas a denunciar el hecho. Añadiendo al delito de pronunciar palabras contra España, los testigos afirmaron que José Vela se encontraba convenciendo a los mulatos de Nacaome para que se sublevasen y lo declarasen teniente de partido. Ateniéndose a la gravedad del caso, los jueces locales apresaron al acusado y le decomisaron todos sus bienes, pasando estos a la posesión de su hermano. Ya que el delito era de gravedad, la justicia local no podía conducir el proceso, debiéndose remitir el acusado al Intendente en Comayagua. Esto era ventajoso para José Vela, ya que el juez de Nacaome estaba sesgado en su contra, declarando que "si semejantes expresiones hubiera proferido en España tres minutos tenía de vida" (Lindo, 1811, p.13). El expediente concluye con la remisión del reo a las cárceles de la capital de la provincia, no habiendo constancia de su sentencia, pero sí sabiéndose que se le había otorgado la oportunidad de salir por fianza.

Este primer caso es de especial notoriedad porque el acusado no solamente se había declarado a favor de Napoleón, enemigo de España en aquel entonces, sino que también había expresado que las ayudas monetarias solicitadas por el gobierno español se utilizaban no en la guerra, sino en los negocios particulares de los ministros. Estos sentimientos expresados por José Vela son sintomáticos del descontento que los pobladores de América tenían con el Imperio Español y cobrarían mayor peso al irse acercando la fecha de Independencia de Centroamérica. La persecución jurídica enfrentada por José Vela demuestra que los españoles tenían, para inicios del siglo XIX, un control endeble de sus colonias, dependiendo su mandato de silenciar a las voces disidentes para evitar que se propagasen las ideas contrarias a su régimen.

El siguiente caso a exponer corresponde a 1817, presentándose la denuncia de una manera curiosa: cuando el Alcalde Mayor de Tegucigalpa inició diligencias para averiguar quién era el autor de unos pasquines sediciosos pegados en las puertas de varias casas de la ciudad, uno de los testigos aprovechó la ocasión para acusar a un soldado llamado José Faustino Galindo de comportamiento revolucionario. Que la denuncia se haya realizado de esta manera solamente indica el ambiente de polarización política en el que se 
vivía, apoyando algunos al Imperio Español y otros a los movimientos independentistas que en aquel entonces habían surgido en México y Suramérica. Según el acusador, José Galindo andaba diseminando las siguientes noticias:

Muy pronto tendrían que caminar para la guerra de México porque el Señor Morelos entraría a Guatemala a tomar la ciudad para el nuevo Rey de México dentro de sesenta días y habiéndole preguntado de donde había adquirido esta noticia, le respondió que el señor José Chango vecino de la villa de San Antonio inmediata a Comayagua se la había contado: que habiéndole replicado que no podía ser cierto porque Morelos hacía tiempo lo habían decapitado dijo que el mismo Chango había dicho que era falso, que Morelos todavía vivía. (Gutiérrez, 1817, p.4).

Esta acusación es interesante, porque el mismo acusador admitía su inverosimilitud. Ciertamente, el Padre José María Morelos había sido ejecutado públicamente por el Imperio Español en 1815, después de una fallida revolución en México, por lo que las noticias de que este se hallaba vivo y que estaba pronto a capturar la ciudad de Guatemala con su ejército no podían ser ciertas. No obstante, $\tan$ siquiera sugerir que una armada rebelde podía deponer al Presidente de la Audiencia de Guatemala era considerado aliciente a la insurrección en este contexto histórico, en el cual las colonias suramericanas habían ya logrado importantes victorias por sobre los españoles y en México se anunciaban nuevos rumores de guerra.

Los testigos pasaron y se apilaron las declaraciones en contra de José Galindo, a quien además le atribuyeron una historia de que un mercader portaba monedas en las cuales estaba grabado el rostro del Padre Morelos. El acusado fue capturado y el proceso se condujo con un marcado sesgo en su contra. Al tratarse de un sospechoso, las autoridades de Honduras intentaron asociarlo con los pasquines revolucionarios que circulaban en Tegucigalpa, agravando así sus cargos. Galindo negó todas las acusaciones, pero de poco le sirvió. Fue pasado a declarar en más de tres ocasiones, en las cuales los jueces insistieron en su culpabilidad y le solicitaron admitiera sus delitos para así aligerar la condena. Convencidos de la culpa de Galindo, los jueces decidieron acusarle de andar "profiriendo expresiones ofensivas al Rey nuestro señor como revolucionarias con perjuicio de la tranquilidad pública" (Gutiérrez, 1817, p.63) y de faltar a la verdad en sus confesiones.

En tiempos normales José Galindo hubiera sido condenado con toda certeza, pero, la suerte estuvo de su lado. El 27 de junio de 1817, el Rey otorgó un indulto general a los presos de la mayoría de delitos, salvo aquellos de excesiva gravedad, como el homicidio. Los jueces de Honduras enviaron el expediente a la Real Audiencia de Guatemala, en donde los oidores de la Sala de Indulto decidieron que José Galindo se encontraba comprendido dentro de la gracia del monarca. El 22 de abril de 1818, se envió a los juzgados de Tegucigalpa esta decisión, quedando libre el acusado.

El último caso a tratar se gestó en septiembre de 1820 , menos de un año antes de declarada la independencia de Honduras con relación a España. Esta fecha no es coincidente, ya que para el año de 1820 las provincias sudamericanas se habían declarado ya independientes y la guerra separatista en México se había reactivado. Debido a estos hechos históricos, las autoridades españolas en Centroamérica se encontraban en un estado de alerta constante para poder así atajar 
cualquier brote insurgente que apareciera en sus jurisdicciones. Naturalmente, esto aumentó la persecución judicial contra aquellas acciones que eran percibidas como amenazantes por las autoridades.

La denuncia fue puesta por Narciso Mallol, el Alcalde Mayor de Tegucigalpa, y fue remitida al Capitán General de Guatemala. Es este un detalle significativo, porque el Alcalde Mayor era también el juez supremo en su jurisdicción $\mathrm{y}$, pues, el encargado de lidiar con los problemas locales. Que la denuncia se haya interpuesto ante el Capitán General significa que Narciso Mallol estaba buscando que se efectuara una intervención armada de parte de aquel funcionario o, que se le proveyera de soldados para mantener en paz su territorio. Si bien en Tegucigalpa no se habían presentado levantamientos armados desde 1812, la situación general del Imperio Español conducía a que el Alcalde Mayor actuara con cautela.

El acusado era un miliciano llamado José Dolores Colindres, que en tiempos de paz se dedicaba a la zapatería. Narciso Mallol presentó los cargos de la siguiente manera:

José Dolores y Colindres de apellido, según creo, que es zapatero, anda solicitando firmas para un escrito contra mi, como Alcalde Mayor. Este es un acto de revolución, que no debe tener jamás lugar, porque la constitución política de la monarquía solo apoya la libertad de que cada individuo pueda reclamar ante la autoridad competente por su voz o la publica mas nunca da facultad para que sean solicitadas a quejar los que ni tienen porque ni han pensando en ello. (Mallol, 1820, p.1).

En este caso en específico, el Alcalde Mayor tenía razón, la Constitución de la Monarquía
Española no facultaba a los individuos para andar solicitando firmas en contra de los funcionarios públicos, mas, el cargo de sedición se presenta exagerado. No podían las acciones de José Dolores constituir una revolución porque este quería deponer al Alcalde Mayor mediante un documento firmado, que sería recibido ya bien por el mismo Alcalde o por el Capitán General. No obstante, en el contexto histórico, estas acciones eran sumamente riesgosas. Apenas en enero de ese mismo año de 1820, Rafael del Riego había promulgado un manifiesto contra Fernando VII, el cual, sin ninguna intención de montar una revolución, había terminado por levantar a los ejércitos de España contra su monarca y en forzarle a reafirmar la Constitución de la Monarquía. En estos sucesos que recuenta el Alcalde Mayor hay un eco histórico de este alzamiento de Rafael del Riego, presintiendo el funcionario de Honduras que él sufriría un mismo destino que el Rey de España que había sido depuesto por un manifiesto de los militares de la península.

Las acusaciones no trascendieron este escrito del Alcalde Mayor, esto por dos motivos: el Capitán General debió haber considerado que el funcionario de Honduras estaba exagerando el comportamiento de un vecino descontento y, porque Narciso Mallol murió seis meses después, en marzo de 1821. Aunque este caso no pasó por los tribunales, es ilustrativo del estado de alerta excesiva en que se encontraban los funcionarios españoles previo a la independencia de Centroamérica y de cómo estos hicieron recurso a las acusaciones de sedición para dar persecución a los elementos sospechosos.

Los tres casos antes expuestos ofrecen una aproximación a cómo se conducía la persecución judicial en los años finales del dominio español en Honduras. En todos los casos, los acusados 
fueron indiciados por meras sospechas, no habiendo evidencia material que los conectase con los hechos delictivos. Igualmente, se percibe en todos los casos como los funcionarios de justicia cargaban a los acusados de un delito en exceso grave, como lo era la sedición, mientras que las acciones de las partes no eran meritorias de tal cargo.

\section{CONCLUSIONES}

- El delito de sedición tuvo un larguísimo desarrollo en la doctrina jurídica castellana. Sus antecedentes más antiguos se remontan al Liber Iudicorum, que fue traducido al romance como el Fuero Juzgo. Posteriormente, los redactores de Las Siete Partidas del Rey Alfonso el Sabio, relacionaron la sedición con una traición al Rey y su dominio, sugiriendo se castigase con pena capital y deshonra perpetua a los descendientes del condenado. Una vez la Corona comenzó a producir leyes exclusivas para América, la legislación contra la sedición se presentó permisiva hacia los indios, pero implacable contra los afrodescendientes. La evolución final de la doctrina se da con la casa de Borbón, cuyas leyes prohibieron criticar a la Corona y la formación de tertulias de oposición política, amenazando de cargos de sedición a los responsables.

- En los años finales de la dominación española en Honduras, el surgimiento de ideas disidentes a la monarquía española fue coartado por las restrictivas leyes en contra de la crítica política. Esto condujo a la formación de un ambiente de tensión social, en el cual los opositores a la Corona tenían que ocultar sus ideas de los funcionarios y también de sus propios vecinos para evitar ser procesados. Esta situación fue erosionando el apoyo que los habitantes de la provincia daban al Rey de España y fue alimentando los deseos de la Independencia.

- Los casos estudiados en esta investigación presentan características similares entre sí. En primera instancia, los acusados fueron perseguidos por simples rumores, lo que demuestra el estado excesivo de alerta en el cual se encontraban las autoridades españolas. Como segundo punto, se puede decir que los cargos realizados contra los acusados no correspondían propiamente a la gravedad de los hechos. Que los habitantes de Honduras fueran perseguidos judicialmente por expresar opiniones políticas contrarias al régimen español, aumentó el resentimiento en la población y provocó que gran mayoría de los pobladores aceptara la separación de la provincia del Imperio Español.

\section{BIBLIOGRAFÍA}

- Baker, J. (2012). Reflections on "doing" legal history. En: Musson, A. y Stebbings, C. (eds.), "Making legal history: approaches and methodologies", pp.7-17. Cambridge: Cambridge University Press

- Constitución Política de la Monarquía Española. (1812). Constitución Política de la Monarquía Española. Cádiz: Cortes de Cádiz

- Fuero Juzgo. (1815). Fuero Juzgo en latín y castellano, cotejado con los más antiguos $y$ preciosos códices por la Real Academia Española. Madrid: Impreso de Cámara de su Majestad. 
- Gutierrez, S. (1817). Causa criminal contra José Galindo, vecino de la villa de San Antonio de Valle de Comayagua, por palabras sediciosas, Tegucigalpa, 13 de agosto de 1817. Fondo Colonial (Documento 4043, caja 127), Archivo Nacional de Honduras.

- $\quad$ Las Siete Partidas del Rey Alfonso. (1843). Segunda y Tercera Partida. Tomo II. París: Lecointe y Laserre Editores

- $\quad$ Las Siete Partidas del Rey Alfonso. (1843b). Sexta y Setena Partida. Tomo IV. París: Lecointe y Laserre Editores

- Lindo, J. (1811). Causa criminal entabla por Joaquín de San Martín contra José Vela por palabras subversivas contra el Estado, Comayagua, 19 de septiembre de 1811. Fondo Colonia (Documento 3429, caja 107), Archivo Nacional de Honduras.

- Lobban, M. (2012). The varieties of legal history. Clio@Themis, (5), pp.1-29. Recuperado de: https://www.cliothemis. com/IMG/pdf/TP_Lobban.pdf

- Mallol, N. (1820). Nota del Alcalde Mayor, Narciso Mallol, para el Comandante Accidental de Armas de Tegucigalpa, da parte de la conducta revolucionaria de José Dolores. Fondo Colonial (Documento 5741, caja 152), Archivo Nacional de Honduras

- Novísima Recopilación de Leyes de España. (1805). Libros X, XI y XII. Tomo V. Madrid: Imprenta de Sancha

- Recopilación de las leyes de los reinos de las Indias. (1841). Libros I y II. Tomo I. Madrid: Boix Editor
- Recopilación de las leyes de los reinos de las Indias. (1841b). Libros III, IV, V, VI y VII. Tomo II. Madrid: Boix Editor

- White, E. (1981). Truth and interpretation in legal history. Michigan Law Review, 79(4), pp.594-615. Recuperado de: http://www. jstor.org/stable/1288285 